\title{
Gelastic seizures associated with hypothalamic hamartomas. An update in the clinical presentation, diagnosis and treatment
}

\author{
José F Téllez-Zenteno' \\ Cesar Serrano-Almeida ${ }^{2}$ \\ Farzad Moien-Afshari' \\ 'Division of Neurology, University \\ of Saskatchewan, Saskatoon, \\ Saskatchewan, Canada; ${ }^{2}$ Department \\ of Clinical Neurosciences, University \\ of Calgary, Calgary, Alberta, Canada
}

Correspondence: José Francisco Téllez-Zenteno Division of Neurology, Department of Medicine, Royal University Hospital 103

Hospital Drive. BOX 26, Room 1622, Saskatoon SK S7N OW8, Canada Email jft084@mail.usask.ca

\begin{abstract}
Gelastic seizures are epileptic events characterized by bouts of laughter. Laughter-like vocalization is usually combined with facial contraction in the form of a smile. Autonomic features such as flushing, tachycardia, and altered respiration are widely recognized. Conscious state may not be impaired, although this is often difficult to asses particularly in young children. Gelastic seizures have been associated classically to hypothalamic hamartomas, although different extrahypothalamic localizations have been described. Hypothalamic hamartomas are rare congenital lesions presenting with the classic triad of gelastic epilepsy, precocious puberty and developmental delay. The clinical course of patients with gelastic seizures associated with hypothalamic hamartomas is progressive, commencing with gelastic seizures in infancy, deteriorating into more complex seizure disorder resulting in intractable epilepsy. Electrophysiological, radiological, and pathophysiological studies have confirmed the intrinsic epileptogenicity of the hypothalamic hamartoma. Currently the most effective surgical approach is the trancallosal anterior interforniceal approach, however newer approaches including the endoscopic and other treatment such as radiosurgery and gamma knife have been used with success. This review focuses on the syndrome of gelastic seizures associated with hypothalamic hamartomas, but it also reviews other concepts such as status gelasticus and some aspects of gelastic seizures in other locations.
\end{abstract}

Keywords: epilepsy, gelastic seizures, epilepsy surgery, hypothalamic hamartoma, intractable epilepsy

\section{Historical note and clinical description of gelastic seizures}

Laughing seizures were first described by Trousseau (1877). Trousseau described a patient that had a seizure in a regular clinic visit characterized by vertigo and jerking bursts of laughter. When Trousseau asked the patient why he laughed, the patient was surprised with the question because he was not aware during the spell. Trousseau used the term epileptic vertigo for any 'transient strange phenomena - giddiness, astonishment, ecstasy ... fit of absence', which he regarded as 'identical in nature with violent convulsions'. Some years later Gowers (1881) observed emotions with a cheerful character as a part of a seizure. Daly and Mulder (1957) coined the term "gelastic epilepsy" in 1957. The term comes from the Greek word "gelos" (laughter), to emphasize the main characteristic of these seizures. Gascon and Lombroso (1971) proposed some criteria for gelastic epilepsy including stereotyped recurrence, absence of external precipitants, concomitant manifestations accepted as epileptic, presence of interictal electroencephalography (EEG) abnormalities and absence of conditions that can cause pathologic laughter. Gascon and Lombroso (1971) also suggested the importance of diencephalic lesions in many cases as a cause of the gelastic seizures (GS). 
GS are epileptic events characterized by bouts of laughter (Gascon and Lombroso 1971). Laughter-like vocalization is usually combined with facial contraction in the form of a smile (Pendl 1975). Autonomic features such as tachycardia, flushing, and altered respiration are widely recognized (Cerullo et al 1998). Conscious state may not be impaired, although this is often difficult to asses particularly in young children. Mirth sensation during GS is not frequent and many adults report more commonly an unpleasant epigastric sensation (Striano et al 1999). Some patients describe an urge to laugh that sometimes can be suppressed (Sturm et al 2000). GS are rarely diagnosed at onset. They may be mistaken by normal laughter or misdiagnosed as infantile colic (Penfold et al 1978; Tassinari et al 1994). The complexity of the diagnosis is based on the fact that ictal and interictal EEG usually are normal or with nonspecific findings. Some patients can have coexistence of gelastic and dacrystic seizures. Dacrystic seizures (DS) were described by Sethi and Rao (1976). Dacrystic episodes can present in clusters at sleep onset, some patients can moan at the onset, with face-flushing that rapidly evolves into crying, associated with facial oro-alimentary automatisms (Lopez-Laso et al 2007).

\section{Localization of gelastic seizures}

GS have been related classically with hypothalamic hamartomas (HHs), although several descriptions have mentioned other locations (Harvey and Freeman 2007). Mohamed and colleagues (2007) reported a case of a patient with GS originated over the anterior cingulate region. The seizure onset was demonstrated with EEG and magnetoencephalography (MEG) and the patient became seizure-free after resection. Other cases in the cingulate region have been described before (McConachie and King 1997). Some reports have described GS with frontal onset. Sartori and colleagues (1999) reported a young patient with GS, where the frontal seizure onset was demonstrated by conventional EEG and single photon emission computed tomography (SPECT). This patient did not have a HH and was successfully treated with medication. Garcia and colleagues (2000) reported another case with frontal onset in a three-and-ahalf-year-old baby who was successfully treated with vigabatrin. The focal origin was demonstrated with scalp EEG and the magnetic resonance imaging (MRI) did not show a HH. Shin and colleagues (2006) described another case where the seizure onset was localized in the parietal area. Finally some authors have presented convincing reports of GS from the temporal area. Dericioglu and colleagues (2005) reported a patient with GS associated with an area of cortical dysplasia over the right temporal area. Interictal and ictal EEG were concordant with the lesion demonstrated in the MRI. The patient had a temporal lobectomy and became seizure free. On the other hand, the localization for dacrystic seizures is similar to patients with GS. Reports of patients with coexistence of both types of seizures are associated with HHs (Lopez-Laso et al 2007), although (Kahane et al 2003) some reports have described dacrystic seizures in patients with temporal epilepsy (de Seze et al 1995; Dan and Boyd 1998).

\section{Syndrome of hypothalamic hamartoma and gelastic seizures}

GS are almost always the first seizure manifestation of $\mathrm{HH}$. Only rarely other types of seizures are the first presentation of HH. GS start in infancy in over one third of patients (Maixner 2006). Neonatal onset of seizures is widely reported, as early as the first day (Kito et al 2001). GS usually occur with high frequency and periodicity, especially in children.

The natural history of children who present with early onset of GS is the progression to intractable epilepsy (Berkovic et al 1988). Typically this occurs between the ages of 4 to 10 years and involves the presence of multiple types of seizures, including complex partial seizures with or without secondary generalization, generalized tonic-clonic seizures and drop attacks (Brandberg et al 2004; Striano et al 2005). Also when GS appear during the neonatal period, the association with infantile spasms has been described (Gomibuchi et al 1990). Only a few reports have described control of GS with medication (Mullatti 2003), in general all the studies have shown that patients with gelastic epilepsy eventually become intractable to medication (Brandberg et al 2004; Striano et al 2005; Maixner 2006). However, not all the children progress to intractability. Close to $25 \%$ can have a more benign course, without the development of an epileptic encephalopathy and with preserved cognition (Arzimanoglou et al 2003). Also some studies have reported a more benign course when GS are associated with the Pallister Hal syndrome (PHS). This syndrome is an autosomal dominant inheritable disorder characterized by HHs, polydactyly, laryngeal malformations such as bifid epiglottis, pulmonary segmentation anomalies, imperforate anus, and panhypopituitarism. In the study of Boudreau and colleagues (2005), patients with PHS had less frequent and less severe seizures. It has been estimated that $20 \%$ or $25 \%$ of patients with PHS have gelastic or other type of seizures (Biesecker 2003). Another 25\% of patients can have learning disabilities, developmental 
delay or mental retardation. On the other hand, patients with PHS have more frequent endocrinologic abnormalities than patients with the syndrome of GS associated with $\mathrm{HH}$, and some of them can develop panhypopituitarism (Biesecker 2003).

The pattern of GS may change over time, especially when patients become adults. Patients can have preservation of frequency and intensity of seizures, but it has been reported that patients can experience disappearance or change in the seizure semiology, experiencing reduction in the gelastic expression and only having a few seconds of laughter (without subjective mirth) to having an "urge to laugh" (Arzimanoglou et al 2003; Kerrigan et al 2005).

Clinical presentation is different in adult patients. Mullatti (2003) described a series of 14 adult patients with GS and $\mathrm{HHs}$ and some observations are interesting and different from children. Compared with children, adult patients have a less severe epilepsy syndrome, less severe learning and behavior difficulties, and better occupation and social status. Also, it has been described that adult patients have a better response to surgical treatment and some of them could be controlled with medication (Mullatti 2003).

The presence of cognitive problems in patients with GS has been reported extensively (Berkovic et al 1988). Quiske and colleagues (2006) performed comprehensive neuropsychological testing in 13 patients with GS associated with HHs. In this study more than half of the patients displayed deficits in a broad range of cognitive functions, expressed mostly in visual and verbal learning and memory. According to the authors some of the deficits could correlate with diseaserelated characteristics representing the severity of the epilepsy or the size of the underlying lesion. Other studies have shown similar findings (Deonna and Ziegler 2000; Frattali et al 2001; Nguyen et al 2003). In general the majority of authors agree that the presence of cognitive dysfunction is more frequent in patients with intractable epilepsy and patients with a long history of seizures (Deonna and Ziegler 2000; Nguyen et al 2003). On the other hand some authors have reported that the severity of the cognitive dysfunction is more frequent in patients with large HHs (Quiske et al 2006).

Another issue that has been addressed in patients with $\mathrm{GS}$ and $\mathrm{HH}$ is the presence of psychiatric comorbidity. Weissenberger and colleagues (2001) performed structured interviews in 12 patients with GS using as controls, the siblings of patients. Children with GS and $\mathrm{HH}$ displayed a higher rate of comorbid psychiatric conditions than controls, these included oppositional defiant disorder (83.3\%), attention-deficit/hyperactivity disorder (75\%), high rates of conduct disorder (33.3\%), speech retardation/learning impairment (33.3\%), and anxiety and mood disorders (16.7\%). Significant rates of aggression were noted, with $58 \%$ of the seizure patients meeting criteria for the affective subtype of aggression and 30.5\% having the predatory aggression subtype. Affective aggression was significantly more common $(\mathrm{p}<0.05)$. Same observations have been reproduced in other series of patients with GS and $\mathrm{HH}$ (Brandberg et al 2004; Maixner 2006). The risk factors associated with the presence of psychiatric comorbidity are unknown, although some authors suggest that patients with frequent seizures are more predisposed to having this type of comorbidity (Prigatano 2007).

Precocious puberty is a clinical finding that has been reported frequently in patient with GS associated with $\mathrm{HH}$. On the other hand HHs, are not associated with other endocrinologic abnormalities such as growth failure, diabetes insipidus, and hypogonadism, in contrast with other hypothalamic pathologies such as astrocytomas, gliomas and craniopharyngiomas where the frequency is higher. This difference has been explained by the nature of the $\mathrm{HH}$, which is a lesion that has a tendency to displace rather than replace normal structures (Freeman et al 2003b). The association between central precocious puberty and GS was first described in a child who had a hypothalamic tumor attached to the tuber cinereum and mamillary bodies (Dott 1939). Garcia Morales and colleagues (2007) reported precocious puberty in 3 of 10 patients, Brandberg and colleagues (2004) in 5 of $12(42 \%)$ patients and Fohlen and colleagues (2003) in 5 of $18(28 \%)$. In general, it has been reported between $30 \%$ to $40 \%$, but some series have not reported its presence (Striano et al 2005).The pathophysiology of precocious puberty has not been established but some observations have been done. Jung and colleagues (2003) analyzed the localization of the $\mathrm{HH}$ and the correlation with the clinical symptoms. Ninety-one percent of HHs in patients with isolated precocious puberty revealed a parahypothalamic position without affecting the third ventricle. Some authors have postulated that the mechanism of precocious puberty in patients with $\mathrm{HH}$ is related with the activation of endogenous human luteinizing hormone-releasing hormone gene (LHRH) secretion via astroglial-derived factors and induction of hypothalamic pubertal neuroendocrine function by $\mathrm{HH}$ secretion of transforming growth factor (Jung and Ojeda 2002).

\section{Pathophysiology of gelastic seizures}

Many advances have been achieved regarding the pathophysiology of GS in recent years. Currently it is very well 
known that the $\mathrm{HH}$ is the source for the seizures in these patients. The clinical evidence is as follows; a) the production of laughter and GS from the stimulation of the $\mathrm{HH}$ with depth electrodes (Cascino et al 1993; Kahane et al 2003), b) the recording of ictal fast activity from the $\mathrm{HH}$ during GS using intracranial recordings (Kuzniecky et al 1997; Kahane et al 2003), c) the observation of ictal HH hyperperfusion and hypermetabolism with SPECT and positron emission tomography (PET) (Kuzniecky et al 1997; DiFazio and Davis 2000; Palmini et al 2005), and d) the resolution of seizures with resection, ablation, or irradiation of the $\mathrm{HH}$ (Regis and Roberts 1999; Rosenfeld et al 2001; Kuzniecky and Guthrie 2003; Regis et al 2004).

Recent advances have demonstrated intrinsic epileptogenicity of the HH. Two populations of neurons have been shown in HH (small and large neurons). Small neurons are spontaneously firing neurons that express GABA receptors, making them inhibitory in nature (Fenoglio et al 2007). The second group are large, pyramidal like neurons that hyperpolarize in repose to GABA agonist. It is proposed that the chronic epileptogenesis of $\mathrm{HH}$ is related with the cluster of small GABAergic neurons, firing action potentials spontaneously and synapse onto the large pyramidal neurons, synchronizing the activity of the large output neurons ( $\mathrm{Wu}$ et al 2005, 2007). Alternative theories suggest that the small neurons could have similarities in morphology and function with neurons from lesions of cortical dysplasia, being potentially epileptogenic (Fenoglio et al 2007). Also the possibility of ephaptic mechanisms, possibly trough gap junction and astroglial involvement has been suggested (Fenoglio et al 2007).

\section{Electrophysiology and type of seizures in patients with gelastic seizures associated with $\mathrm{HH}$}

Scalp EEG is very limited in order to show epileptiform activity due to the deep localization of the lesion and the complex connections of the HHs (Maixner 2006). In early stages of the illness, the interictal EEG usually is normal (Arzimanoglou et al 2003; Mullatti et al 2003). After some years of evolution, electrographic changes consistent with lobar involvement may become apparent (Freeman et al 2003a). The EEG in many patients shows multifocal epileptiform activity (Kitajima et al 1998). Also in children it is possible to see ictal and interictal generalized polyspike waveform discharges (Freeman et al 2003a).
Complex partial seizures are frequently seen in patients with GS associated with HHs. In some patients the distinction between GS and complex partial seizures can be difficult to ascertain on history and on video analysis (Harvey and Freeman 2007). Epigastric discomfort, fear, oral and bimanual automatisms, axial movements and complex bi-pedal movements are frequently reported during complex partial seizures in patients with HH (Kuzniecky et al 1997; Maixner 2006). Sweetman and colleagues (2007) reported 6 patients that were misdiagnosed with gastroesophageal reflux; all of them had GS associated with HHs. The symptoms in this group of patients included regurgitation, irritability, arching, choking, and apnea. Reported focal motor features including head and eye version, asymmetric tonic posturing, tonic or clonic lower facial contraction, and limb jerking. Some selected series have reported typical temporal lobe seizures with electrographic changes in the temporal area and where the consideration of a temporal lobectomy was performed (Cascino et al 1993). EEG in patients with complex partial seizures can show intermittent focal slowing or epileptiform activity (Machado et al 1991). Epileptiform activity can be present over the frontal or the temporal region (Cascino et al 1993). In some patients the ictal EEG during complex partial seizures may show diffuse attenuation, but this is followed by localized or regionalized fast rhythms or spike wave (Cascino et al 1993). It has been demonstrated that the behavioral and motor manifestations constituting the nongelastic component and the complex partial seizures in these patients represent spread of seizure activity from the $\mathrm{HH}$ to specific frontal, temporal or other cortical regions (Leal et al 2006). In fact, some authors have shown that cortical resections are usually not successful in order to control the seizures (Cascino et al 1993).

The presence of generalized tonic-clonic seizures (GTCS) has been reported commonly in patients with GS associated with $\mathrm{HH}$. Large series report a frequency of GTCS of approximately $70 \%$ ( $\mathrm{Ng}$ et al 2006), although the frequency is lower in nonsurgical series and maybe in adult patients (Mullatti 2003; Mullatti et al 2003). In series with long-standing follow up, it has been shown that usually GTCS come after some years of having GS and complex partial seizures and their development is accompanied with more widespread EEG abnormalities and neurobehavioral disturbances (Berkovic et al 1988; Freeman et al 2003a; Striano et al 2005). In patients with GTCS the EEG frequently shows an increase in the amount of interictal generalized spike wave activity during wakefulness and 
sleep and it is possible to see secondary bilateral synchrony. Also presence of continuous slow spike wave, paroxysmal fast activity and electrodecremental events, in a similar way as patients with Lennox-Gastaut Syndrome has been reported (Freeman et al 2003a). The pathogenesis of GTCS and EEG abnormalities in patients with $\mathrm{HH}$ is unknown. The findings supporting a cortical involvement related with cerebral dysgenesis are controversial (Berkovic et al 1988), and the favorable results with $\mathrm{HH}$ surgery point to the possibility of seizure propagation from the $\mathrm{HH}$ to the cortex. However some reports using depth electrodes have shown that during tonic seizures, diffuse cortical fast activity can be seen, with no prior activity in the $\mathrm{HH}$ (Kahane et al 2003). Some authors have mentioned that the development of GTCS and generalized EEG abnormalities may represent secondary epileptogenesis or a kindling effect in the neocortex, as a consequence of repetitive epileptiform discharges from the $\mathrm{HH}$ to the cerebral cortex (Kerrigan et al 2005; Munari et al 1995, 1997). Over the years it has been considered that the neocortex in patients with GS and HHs becomes a secondary focus to the primary source of seizures in the $\mathrm{HH}$, with potential postoperative resolution in patients who have not reached the irreversible, independent stage (Freeman et al 2003a).

\section{Determinants of clinical manifestations}

Some associations have been shown between the localization of the $\mathrm{HH}$ and the clinical profile, although these are not constant. For example, some studies have shown that size is important in order to determine the seizure severity. In the series of Mullati and colleagues (2003) patients with $\mathrm{HH}$ between 4 to $10 \mathrm{~mm}$ had late onset seizures more frequently than patients with smaller HH. Freeman and colleagues (2004) performed the clinical correlation between clinical findings and the size and localization of HH. HHs associated with epilepsy had more ventricular attachment and with connection to one or the two mammillary bodies. On the other hand, hamartomas associated with only precocious puberty were more frequently related with the tuber cinereum (predominantly intraventricular versus predominantly interpeduncular) (Freeman et al 2004). Some studies have suggested that small HHs can have less severe seizures, less cognitive problems and a lower frequency of precocious puberty (Sturm et al 2000; Striano et al 2002). Also the asymmetry of $\mathrm{HH}$ attachment can correlate with asymmetries in clinical seizure characteristics (Harvey and Freeman 2007).

\section{Status gelasticus}

The term status gelasticus was coined by Palmini and colleagues (2005). He described a case report of a patient with continuous GS associated with a $\mathrm{HH}$. The patient was treated successfully with carbamazepine. After this description other reports have described this rare clinical phenomenon associated with HHs (Ng and Rekate 2005), and recently Pustorino and colleagues (2007) reported a patient with intractable symptomatic focal epilepsy where a status gelasticus was triggered by levetiracetam.

\section{Treatment of patients with gelastic seizures and hypothalamic hamartomas}

GS are characteristically refractory to medical treatment and the progressing epileptic process eventually leads to deterioration of cognitive and behavioral function (Palmini et al 2002). Despite the use of higher dose and several combinations of antiepileptic drugs (AEDs), seizure freedom or good seizure control is rarely achieved in this group of patients (Harvey and Freeman 2007). Patients with intractable epilepsy associated with HHs should be investigated with intracranial recording in order to clarify the seizure onset in the HH. In many cases extrahypothalamic coverage should be performed to evaluate spread of seizures and potential extratemporal onset (Cascino et al 1993). Currently it is recognized that the best treatment in these patients is the ablation of the HH. This can be done with different procedures including surgery and nonsurgical treatments such as radiosurgery (Cascino et al 1993).

Different surgical procedures have been attempted to control GS in patients with HHs. Focal cortical resections and callosotomies were performed unsuccessfully in the mid 90s based on intracranial EEG monitoring results and the presence of drop attacks in patients with intractable epilepsy associated to HHs (Cascino et al 1993). Vagal nerve stimulation has been used, but the results are equivocal (Murphy et al 1995). Evidence about the role of the $\mathrm{HH}$ in the genesis of GS has promoted the concept of $\mathrm{HH}$ resection, ablation, or disconnection as surgical goals.

The location and anatomical features of HHs have shown correlation with the clinical presentation and the appropriate selection of the surgical approach. Valdueza and colleagues (1994) classified HHs as pedunculated or type I and sessile or type II. Pedunculated HHs have a narrow attachment to the tuber cinereum (type Ia) or the angle between the tuber cinereum and a mamillary body 
(type Ib). These HHs do not disturb the hypothalamic region and predominantly produce precocious puberty. Sessile HHs have a broad attachment to the floor of the third ventricle and the mamillary bodies. This type of HHs may produce distortion of the third ventricle and are commonly associated with GS. Arita and colleagues (1999) proposed a newer classification of HHs based on MRI characteristics. They described two categories, parahypothalamic and intrahypothalamic types, which correspond to pedunculated and sessile hamartomas, respectively.

Surgical resection of $\mathrm{HHs}$ has been performed by approaches that reach the lesion from below or from above. Surgical approaches from below are performed by a pterional or frontotemporal craniotomies that access the HH through a transsylvian, subtemporal, transfrontal or subfrontal/lamina terminalis corridor (Machado et al 1991; Valdueza et al 1994; Likavec et al 2000; Mottolese et al 2001; Palmini et al 2002). These approaches were initially used because most of the neurosurgeons are more confident with them and they offer a shorter route to reach HHs. During these approaches, the surgeon dissects delicate vascular and neuroendocrine structures, thus surgical complications are not unusual and include stroke, third nerve paresis, syndrome of inappropriate antidiuretic hormone secretion, and hyperphagia (Palmini et al 2002). Although surgical approaches from below are suitable to remove pedunculated HHs, they have technical limitations to obtain satisfactory resection of sessile $\mathrm{HHs}$ which are associated to GS. Likavec and colleagues (2000) reviewed the surgical literature and reported that $42.9 \%$ of patients undergoing craniotomies improve or obtain seizure freedom. These unsuccessful results created the need to find different surgical approaches that could achieve better resection of the intraventricular component of sessile HHs and offer better seizure control.

Rosenfeld and colleagues (2001) proposed to reach the HH from above by performing a transcallosal-interforniceal approach which had been used previously to resect lesions affecting the third ventricle (Apuzzo et al 1982). The transcallosal-interforniceal approach allows disclosing the entire intraventricular component of the $\mathrm{HH}$ and achieves complete or nearly complete $(>95 \%)$ excision of sessile HH (Apuzzo et al 1982). This surgical approach has shown a significant better seizure control than previous approaches from below. A recent publication from Royal Children's Hospital in Melbourne and the Barrow Neurological Institute in Phoenix, AZ reported that 52\% to $54 \%$ of the patients are seizure free and $24 \%$ to $35 \%$ have $>90 \%$ seizure reduction (Feiz-Erfan et al 2005). Harvey and colleagues (2003) report the seizure outcome of 29 patients with a mean follow up of 30 months using this approach. In this study 15 patients were seizure free, 7 patients had $>90 \%$ reduction in seizure frequency, 3 had $55 \%$ to $80 \%$ reduction and 4 had $<40 \%$ reduction. The fornix and mammillary body may be injured during the transcallosal-interforniceal approach, explaining an $8 \%$ to $14 \%$ risk of short-term memory impairment. Although it may be a permanent deficit it seems tolerable considering the overall improvement of cognitive function (Feiz-Erfan et al 2005; Rosenfeld and Feiz-Erfan 2007). Other complications reported with this procedure that have been reported are third nerve paresis, hemiparesis, appetite stimulation and weight gain, transient hypersomnolence and hyperthermia, and transient endocrine abnormalities such as hypothyroidism and diabetes insipidus (Rosenfeld and Feiz-Erfan 2007).

Delalande and Fohlen (2003) have considered that surgical disconnection, instead of surgical resection of the $\mathrm{HH}$, is an effective and safe alternative. The intrinsic epileptogenic activity and stable nature of the $\mathrm{HH}$ support the rationale of blocking the epileptic spreading pathway to control GS. Depth electrodes inserted into the HH have shown immediate intraoperative disappearance of epileptic discharges from the $\mathrm{HH}$, during endoscopic disconnection (Choi et al 2004). The disconnection is performed by endoscopic and/or pterional approach depending on the plane of insertion of the $\mathrm{HH}$ on the hypothalamus (Delalande and Fohlen 2003). Procaccini and colleagues (2006) reported a series of 33 patients who underwent disconnection by pterional and/or robot-assisted endoscopic approach. All patients except one improved clinically. Seizure freedom (Engel Class 1) was seen in 16 patients $(48.5 \%)$ and significant improvement (Engel Classes 2 and 3 ) in 16 patients (48.5\%). Patients who only required endoscopic disconnection had better control of seizures; thus, $90 \%$ of them were seizure free (Engel Class 1) and 10\% showed significant improvement (Engel Class 3).

Stereotactic radiofrequency thermocoagulation of the $\mathrm{HH}$ has been used as a minimally invasive surgical approach. A small burr-hole or twist-drill opening is required to allow stereotactic placement of the stimulating/lesioning electrode (Parrent 1999). Kuzniecky and colleagues (1997) reported total seizure control in a single case during a 20-month follow up period. The size of the $\mathrm{HH}$ is an important criterion to select the patient, as better seizure control has been found in small lesions. Homma and colleagues (2007) 
Table I Studies using gamma knife to treat patients with gelastic seizures

\begin{tabular}{|c|c|c|c|c|c|}
\hline Authors & $\begin{array}{l}\text { Number } \\
\text { of patients }\end{array}$ & $\begin{array}{l}\text { Age range } \\
\text { (Mean, median) }\end{array}$ & Follow up & $\%$ seizure free & $\begin{array}{l}\text { Precocious } \\
\text { puberty }\end{array}$ \\
\hline Mathieu et al 2006 & 4 & $5-29 Y$ & 22 months & $\begin{array}{l}3 \text { patients had } \\
\text { some improvement }\end{array}$ & No data \\
\hline Regis et al 2006 & 27 & $3-50 Y(19.2,17.2)$ & 36 months & $37 \%$ & $74 \%$ \\
\hline Barajas et al 2005 & 3 & 3 and 12 and $15 Y$ & $30-50$ months & $\begin{array}{l}0 \% \text { but all patients } \\
\text { had significant } \\
\text { decrease in } \\
\text { frequency }\end{array}$ & $33 \%$ \\
\hline Regis et al 2005 & 10 & $\mathrm{I}-32 \mathrm{Y}(\mathrm{I}, \mathrm{I}, \mathrm{3} .5)$ & $\begin{array}{l}>12 \text { month median } \\
28 \text { months }\end{array}$ & $40 \%$ & $30 \%$ \\
\hline
\end{tabular}

recently published a series of five patients with small $\mathrm{HHs}$ and intractable GS. All of them had HHs less than $10 \mathrm{~mm}$ in diameter and total gelastic seizure control was obtained in four patients. Sterotactic radiofrequency thermocoagulation is a safe procedure and despite of some postoperative transitory hypothalamic symptoms, no permanent neurologic deficits have been reported (Kuzniecky et al 1997; Parrent 1999; Homma et al 2007).

The first case of a HH successfully treated with gamma knife surgery (GKS) was reported by Arita and colleagues (1998). Regis and colleagues (2007) enrolled 60 patients with HH treated with gamma knife between 1999 and 2005. All the patients were treated with gamma knife in a prospective multicentre trial. In this trial $59.2 \%$ of the patients had an excellent result with a dramatic behavioral and cognitive improvement, $37 \%$ are seizure free or have only rare nondisabling seizures in $22.2 \%$ (Regis et al 2006). Other small series also suggested the efficacy of gamma knife in the treatment of patients with GS associated with HH (Barajas et al 2005; Selch et al 2005; Mathieu et al 2006). Despite the popularity of this therapy the main disadvantage of the procedure is the delay of its effect. In the majority of patients, seizures start to decrease around 6 months after the procedure; however there is a great variability in the timing of the response (Rosenfeld et al 2001). For this reason some authors advised the surgical approach for patients with intractable epilepsy and severe behavior abnormalities. Other disadvantages of the procedure are the lower seizure outcome compared with the transcallosal approach and the possibility of radiation damage to the surrounding hypothalamus and visual pathways. Finally Regis and colleagues (2006) and other authors have suggested the use of gamma knife in patients with residual lesions after surgery. In Tables 1, 2, and 3 we summarize all the studies (case reports, not included) reporting different outcomes in patients with GS associated with HHs that have received different treatments.

\section{Conclusions}

HHs are rare tumors associated with the triad of gelastic epilepsy, precocious puberty, and developmental delay. HHs are diagnosed more frequently during childhood and eventually the majority of the patients develop intractable epilepsy. GS is the first type of seizure that these patients develop, although other type of seizures are frequently present such as complex partial seizures, generalized tonic-clonic seizures, drop attacks and infantile spasms. Progressive cognitive deficits and the presence of important psychiatric comorbidity are widely described. When the syndrome appears in adults, the prognosis may be better, with less severe epilepsy and better neurophysiological outcomes. Due to the intractability of these patients, many of them will

Table 2 Studies using radiosurgery/stereotactic radiation to treat patients with gelastic seizures

\begin{tabular}{llllll}
\hline Authors & $\begin{array}{l}\text { Number } \\
\text { of patients }\end{array}$ & $\begin{array}{l}\text { Age range, } \\
\text { Mean, or median }\end{array}$ & Follow up & $\%$ seizure free & Precocious puberty \\
\hline Schulze-Bonhage 2007 & 15 & $3-20$ Y (mean I3.9Y) & 36 months & $20 \%$ & $20 \%$ \\
Quiske et al 2007 & 14 & I5-43Y (mean I5.4 I0.5Y) & 3 months & $\begin{array}{l}0 \% \text { free but 50\% } \\
\text { reduction of frequency }\end{array}$ & No data \\
Schulze-Bonhage 2004 & 6 & $9-3$ IY (mean I7Y) & 12 months & $33 \%$ & $33 \%$ \\
\hline
\end{tabular}




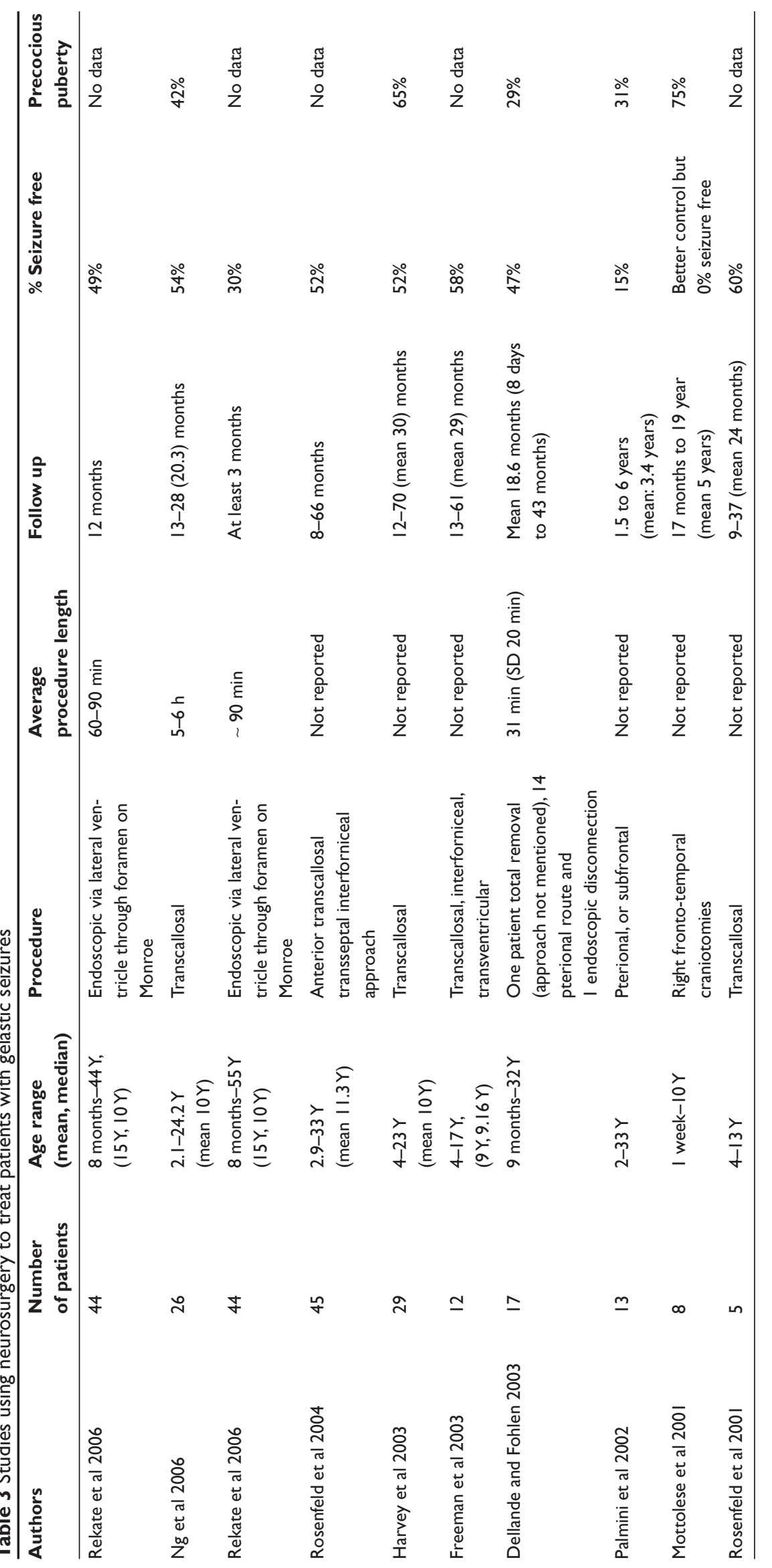


require intracranial investigations in order to have surgery. The surgical procedure that has shown the best seizure outcome is the transcallosal approach but other nonsurgical procedures such as radiosurgery are gaining popularity because of good results.

\section{Disclosure}

The authors report no conflicts of interest in this work.

\section{References}

Apuzzo ML, Chikovani OK, Gott PS, et al. 1982. Transcallosal, interfornicial approaches for lesions affecting the third ventricle: surgical considerations and consequences. Neurosurgery, 10:547-54.

Arita K, Ikawa F, Kurisu K, et al. 1999. The relationship between magnetic resonance imaging findings and clinical manifestations of hypothalamic hamartoma. J Neurosurg, 91:212-20.

Arita K, Kurisu K, Iida K, et al. 1998. Subsidence of seizure induced by stereotactic radiation in a patient with hypothalamic hamartoma. Case report. J Neurosurg, 89:645-8.

Arzimanoglou AA, Hirsch E, Aicardi J. 2003. Hypothalamic hamartoma and epilepsy in children: illustrative cases of possible evolutions. Epileptic Disord, 5:187-99.

Barajas MA, Ramirez-Guzman MG, Rodriguez-Vazquez C, et al. 2005. Gamma knife surgery for hypothalamic hamartomas accompanied by medically intractable epilepsy and precocious puberty: experience in Mexico. J Neurosurg, 102(Suppl):53-5.

Berkovic SF, Andermann F, Melanson D, et al. 1988. Hypothalamic hamartomas and ictal laughter: evolution of a characteristic epileptic syndrome and diagnostic value of magnetic resonance imaging. Ann Neurol, 23:429-39.

Biesecker LG. 2003. Heritable syndromes with hypothalamic hamartoma and seizures: using rare syndromes to understand more common disorders. Epileptic Disord, 5:235-8.

Boudreau EA, Liow K, Frattali CM, et al. 2005. Hypothalamic hamartomas and seizures: distinct natural history of isolated and Pallister-Hall syndrome cases. Epilepsia, 46:42-7.

Brandberg G, Raininko R, Eeg-Olofsson O. 2004. Hypothalamic hamartoma with gelastic seizures in Swedish children and adolescents. Eur $J$ Paediatr Neurol, 8:35-44.

Cascino GD, Andermann F, Berkovic SF, et al. 1993. Gelastic seizures and hypothalamic hamartomas: evaluation of patients undergoing chronic intracranial EEG monitoring and outcome of surgical treatment. Neurology, 43:747-50.

Cerullo A, Tinuper P, Provini F, et al. 1998. Autonomic and hormonal ictal changes in gelastic seizures from hypothalamic hamartomas. Electroencephalogr Clin Neurophysiol, 107:317-22.

Choi JU, Yang KH, Kim TG, et al. 2004. Endoscopic disconnection for hypothalamic hamartoma with intractable seizure. Report of four cases. J Neurosurg, 100:506-11.

Daly DD, Mulder DW. 1957. Gelastic epilepsy. Neurology, 7:189-92.

Dan B, Boyd SG. 1998. Dacrystic seizures reconsidered. Neuropediatrics, 29:326-7.

de Seze J, Caparros-Lefebvre D, Girard-Buttaz I, et al. 1995. [Dacrystic and asystolic epileptic seizures]. Rev Neurol (Paris), 151:413-5.

Delalande O, Fohlen M. 2003. Disconnecting surgical treatment of hypothalamic hamartoma in children and adults with refractory epilepsy and proposal of a new classification. Neurol Med Chir (Tokyo), 43:61-8.

Deonna T, Ziegler AL. 2000. Hypothalamic hamartoma, precocious puberty and gelastic seizures: a special model of "epileptic" developmental disorder. Epileptic Disord, 2:33-7.

Dericioglu N, Cataltepe O, Tezel GG, et al. 2005. Gelastic seizures due to right temporal cortical dysplasia. Epileptic Disord, 7:137-41.
DiFazio MP, Davis RG. 2000. Utility of early single photon emission computed tomography (SPECT) in neonatal gelastic epilepsy associated with hypothalamic hamartoma. J Child Neurol, 15:414-7.

Dott NW. 1939. Surgical aspects of the hypothalamus. In: Le Gross Clark WE, Beattle J, Riddoch G DN (eds). The hypothalamus; morphological, functional and surgical aspects. Edinburg: Oliver and Boyd, pp. 131-85.

Feiz-Erfan I, Horn EM, Rekate HL, et al. 2005. Surgical strategies for approaching hypothalamic hamartomas causing gelastic seizures in the pediatric population: transventricular compared with skull base approaches. J Neurosurg, 103:325-32.

Fenoglio KA, Wu J, Kim DY, et al. 2007. Hypothalamic hamartoma: basic mechanisms of intrinsic epileptogenesis. Semin Pediatr Neurol, 14:51-9.

Fohlen M, Lellouch A, Delalande O. 2003. Hypothalamic hamartoma with refractory epilepsy: surgical procedures and results in 18 patients. Epileptic Disord, 5:267-73.

Frattali CM, Liow K, Craig GH, et al. 2001. Cognitive deficits in children with gelastic seizures and hypothalamic hamartoma. Neurology, 57:43-6.

Freeman JL, Coleman LT, Wellard RM, et al. 2004. MR imaging and spectroscopic study of epileptogenic hypothalamic hamartomas: analysis of 72 cases. AJNR Am J Neuroradiol, 25:450-62.

Freeman JL, Harvey AS, Rosenfeld JV, et al. 2003a. Generalized epilepsy in hypothalamic hamartoma: evolution and postoperative resolution. Neurology, 60:762-7.

Freeman JL, Zacharin M, Rosenfeld JV, et al. 2003b. The endocrinology of hypothalamic hamartoma surgery for intractable epilepsy. Epileptic Disord, 5:239-47.

Garcia A, Gutierrez MA, Barrasa J, et al. 2000. Cryptogenic gelastic epilepsy of frontal lobe origin: a paediatric case report. Seizure, 9:297-300.

Garcia-Morales I, Marinas A, del Barrio A, et al. 2007. [Hypothalamic hamartoma: clinical characteristics. Electroencephalogram and brain magnetic resonance imaging in 10 patients). Neurologia, 22:11-8.

Gascon GG, Lombroso CT. 1971. Epileptic (gelastic) laughter. Epilepsia, 12:63-76.

Gomibuchi K, Ochiai Y, Kanraku S, et al. 1990. [Infantile spasms and gelastic seizure due to hypothalamic hamartoma.] No To Hattatsu, 22:392-4.

Gowers WR. 1881. Epilepsy and other chronic convulsive diseases. New York: William Wood and Company.

Harvey AS, Freeman JL. 2007. Epilepsy in hypothalamic hamartoma: clinical and EEG features. Semin Pediatr Neurol, 14:60-4.

Harvey AS, Freeman JL, Berkovic SF, et al. 2003. Transcallosal resection of hypothalamic hamartomas in patients with intractable epilepsy. Epileptic Disord, 5:257-65.

Homma J, Kameyama S, Masuda H, et al. 2007. Stereotactic radiofrequency thermocoagulation for hypothalamic hamartoma with intractable gelastic seizures. Epilepsy Res, 76:15-21.

Jung H, Neumaier PE, Hauffa BP, et al. 2003. Association of morphological characteristics with precocious puberty and/or gelastic seizures in hypothalamic hamartoma. $J$ Clin Endocrinol Metab, 88:4590-5.

Jung H, Ojeda SR. 2002. Pathogenesis of precocious puberty in hypothalamic hamartoma. Horm Res, 57(Suppl 2):31-4.

Kahane P, Ryvlin P, Hoffmann D, et al. 2003. From hypothalamic hamartoma to cortex: what can be learnt from depth recordings and stimulation? Epileptic Disord, 5:205-17.

Kerrigan JF, Ng YT, Chung S, et al. 2005. The hypothalamic hamartoma: a model of subcortical epileptogenesis and encephalopathy. Semin Pediatr Neurol, 12:119-31.

Kitajima K, Ikeda A, Terada K, et al. 1998. [A case of hypothalamic hamartoma manifesting gelastic seizure and multifocal independent seizure foci.] Rinsho Shinkeigaku, 38:305-10.

Kito M, Yabuta K, Kato S, et al. 2001. Gelastic seizures in clusters in a case of West syndrome after perinatal hypothalamic hemorrhage. J Perinat Med, 29:357-9. 
Kuzniecky R, Guthrie B, Mountz J, et al. 1997. Intrinsic epileptogenesis of hypothalamic hamartomas in gelastic epilepsy. Ann Neurol, 42:60-7.

Kuzniecky RI, Guthrie BL. 2003. Stereotactic surgical approach to hypothalamic hamartomas. Epileptic Disord, 5:275-80.

Leal AJ, Dias AI, Vieira JP. 2006. Analysis of the EEG dynamics of epileptic activity in gelastic seizures using decomposition in independent components. Clin Neurophysiol, 117:1595-601.

Likavec AM, Dickerman RD, Heiss JD, et al. 2000. Retrospective analysis of surgical treatment outcomes for gelastic seizures: a review of the literature. Seizure, 9:204-7.

Lopez-Laso E, Mateos Gonzalez ME, Camino LR, et al. 2007. Giant hypothalamic hamartoma and dacrystic seizures. Epileptic Disord, 9:90-3.

Machado HR, Hoffman HJ, Hwang PA. 1991. Gelastic seizures treated by resection of a hypothalamic hamartoma. Childs Nerv Syst, 7:462-5.

Maixner W. 2006. Hypothalamic hamartomas - clinical, neuropathological and surgical aspects. Childs Nerv Syst, 22:867-73.

Mathieu D, Kondziolka D, Niranjan A, et al. 2006. Gamma knife radiosurgery for refractory epilepsy caused by hypothalamic hamartomas. Stereotact Funct Neurosurg, 84:82-7.

McConachie NS, King MD. 1997. Gelastic seizures in a child with focal cortical dysplasia of the cingulate gyrus. Neuroradiology, 39:44-5.

Mohamed IS, Otsubo H, Shroff M, et al. 2007. Magnetoencephalography and diffusion tensor imaging in gelastic seizures secondary to a cingulate gyrus lesion. Clin Neurol Neurosurg, 109:182-7.

Mottolese C, Stan H, Bret P, et al. 2001. Hypothalamic hamartoma: the role of surgery in a series of eight patients. Childs Nerv Syst, $17: 229-36$.

Mullatti N. 2003. Hypothalamic hamartoma in adults. Epileptic Disord, 5:201-4.

Mullatti N, Selway R, Nashef L, et al. 2003. The clinical spectrum of epilepsy in children and adults with hypothalamic hamartoma. Epilepsia, 44:1310-9.

Munari C, Kahane P, Francione S, et al. 1995. Role of the hypothalamic hamartoma in the genesis of gelastic fits (a video-stereo-EEG study). Electroencephalogr Clin Neurophysiol, 95:154-60.

Munari C, Tassi L, Berta E, et al. 1997. Case of a child with gelastic seizures and hypothalamic hamartoma. Epilepsia, 38:1364-5.

Murphy JV, Hornig G, Schallert G. 1995. Left vagal nerve stimulation in children with refractory epilepsy. Preliminary observations. Arch Neurol, 52:886-9.

Ng YT, Rekate HL. 2005. Emergency transcallosal resection of hypothalamic hamartoma for "status gelasticus". Epilepsia, 46:592-4.

Ng YT, Rekate HL. 2007. Endoscopic resection of hypothalamic hamartoma for refractory epilepsy: preliminary report. Semin Pediatr Neurol, 14:99-105.

Ng YT, Rekate HL, Prenger EC, et al. 2006. Transcallosal resection of hypothalamic hamartoma for intractable epilepsy. Epilepsia, 47:1192-202

Nguyen D, Singh S, Zaatreh M, et al. 2003. Hypothalamic hamartomas: seven cases and review of the literature. Epilepsy Behav, 4:246-58.

Palmini A, Chandler C, Andermann F, et al. 2002. Resection of the lesion in patients with hypothalamic hamartomas and catastrophic epilepsy. Neurology, 58:1338-47.

Palmini A, Van Paesschen W, Dupont P, et al. 2005. Status gelasticus after temporal lobectomy: ictal FDG-PET findings and the question of dual pathology involving hypothalamic hamartomas. Epilepsia, 46:1313-6.

Parrent AG. 1999. Stereotactic radiofrequency ablation for the treatment of gelastic seizures associated with hypothalamic hamartoma. Case report. J Neurosurg, 91:881-4.

Pendl G. 1975. Gelastic epilepsy in tumours of the hypothalamic region. Adv Neurosurg, 3:442-9.

Penfold JL, Manson JI, Caldicott WM. 1978. Laughing seizures and precocious puberty (case report and review of the literature). Aust Paediatr J, 14:185-90.
Prigatano GP. 2007. Cognitive and behavioral dysfunction in children with hypothalamic hamartoma and epilepsy. Semin Pediatr Neurol, 14:65-72.

Procaccini E, Dorfmuller G, Fohlen M, et al. 2006. Surgical management of hypothalamic hamartomas with epilepsy: the stereoendoscopic approach. Neurosurgery, 59:ONS336-ONS344.

Pustorino G, Spano M, Sgro DL, et al. 2007. Status gelasticus associated with levetiracetam as add-on treatment. Epileptic Disord, 9:186-9.

Quiske A, Frings L, Wagner K, et al. 2006. Cognitive functions in juvenile and adult patients with gelastic epilepsy due to hypothalamic hamartoma. Epilepsia, 47:153-8.

Quiske A, Unterrainer J, Wagner K, et al. 2007. Assessment of cognitive functions before and after stereotactic interstitial radiosurgery of hypothalamic hamartomas in patients with gelastic seizures. Epilepsy Behav, 10:328-32.

Regis J, Bartolomei F, de Toffol B, et al. 2000. Gamma knife surgery for epilepsy related to hypothalamic hamartomas. Neurosurgery, 47:1343-51.

Regis J, Hayashi M, Eupierre LP, et al. 2004. Gamma knife surgery for epilepsy related to hypothalamic hamartomas. Acta Neurochir Suppl, 91:33-50.

Regis J, Scavarda D, Tamura M, et al. 2006. Epilepsy related to hypothalamic hamartomas: surgical management with special reference to gamma knife surgery. Childs Nerv Syst, 22:881-95.

Regis J, Scavarda D, Tamura M, et al. 2007. Gamma knife surgery for epilepsy related to hypothalamic hamartomas. Semin Pediatr Neurol, 14:73-9.

Regis Y, Roberts DW. 1999. Gamma knife radiosurgery relative to microsurgery: epilepsy. Stereotact Funct Neurosurg, 72(Suppl 1):11-21.

Rekate HL, Feiz-Erfan I, Ng YT, et al. 2006. Endoscopic surgery for hypothalamic hamartomas causing medically refractory gelastic epilepsy. Childs Nerv Syst, 22:874-80.

Rosenfeld JV, Feiz-Erfan I. 2007. Hypothalamic hamartoma treatment: surgical resection with the transcallosal approach. Semin Pediatr Neurol, 14:88-98.

Rosenfeld JV, Freeman JL, Harvey AS. 2004. Operative technique: The anterior transcallosal transseptal interforniceal approach to the third ventricle and resection of hypothalamic hamartomas. J Clin Neurosci, $11: 738-44$

Rosenfeld JV, Harvey AS, Wrennall J, et al. 2001. Transcallosal resection of hypothalamic hamartomas, with control of seizures, in children with gelastic epilepsy. Neurosurgery, 48:108-18.

Sartori E, Biraben A, Taussig D, et al. 1999. Gelastic seizures: video-EEG and scintigraphic analysis of a case with a frontal focus; review of the literature and pathophysiological hypotheses. Epileptic Disord, 1:221-8.

Schulze-Bonhage A, Homberg V, Trippel M, et al. 2004. Interstitial radiosurgery in the treatment of gelastic epilepsy due to hypothalamic hamartomas. Neurology, 62:644-7.

Schulze-Bonhage A, Ostertag C. 2007. Treatment options for gelastic epilepsy due to hypothalamic hamartoma: interstitial radiosurgery. Semin Pediatr Neurol, 14:80-7.

Selch MT, Gorgulho A, Mattozo C, et al. 2005. Linear accelerator stereotactic radiosurgery for the treatment of gelastic seizures due to hypothalamic hamartoma. Minim Invasive Neurosurg, 48:310-4.

Sethi PK, Rao ST. 1976. Gelastic, quiritarian, and cursive epilepsy: a clinicopathological appraisal. J Neurol Neurosurg Psychiatry, 39:823-8.

Shin HY, Hong SB, Joo EY, et al. 2006. Gelastic seizures involving the right parietal lobe. Epileptic Disord, 8:209-12.

Striano S, Meo R, Bilo L, et al. 1999. Gelastic epilepsy: symptomatic and cryptogenic cases. Epilepsia, 40:294-302.

Striano S, Striano P, Cirillo S, et al. 2002. Small hypothalamic hamartomas and gelastic seizures. Epileptic Disord, 4:129-33.

Striano S, Striano P, Sarappa C, et al. 2005. The clinical spectrum and natural history of gelastic epilepsy-hypothalamic hamartoma syndrome. Seizure, 14:232-9. 
Sturm JW, Andermann F, Berkovic SF. 2000. "Pressure to laugh": an unusual epileptic symptom associated with small hypothalamic hamartomas. Neurology, 54:971-3.

Sweetman LL, Ng YT, Kerrigan JF. 2007. Gelastic seizures misdiagnosed as gastroesophageal reflux disease. Clin Pediatr (Phila), 46:325-8.

Tassinari G, Aglioti S, Pallini R, et al. 1994. Interhemispheric integration of simple visuomotor responses in patients with partial callosal defects. Behav Brain Res, 64:141-9.

Trousseau A. 1877. [De L'Epilepsie.] Clinique Medicale de L'Hotel-Dieu de Paris, pp. 89-155.

Valdueza JM, Cristante L, Dammann O, et al. 1994. Hypothalamic hamartomas: with special reference to gelastic epilepsy and surgery. Neurosurgery, 34:949-58.
Weissenberger AA, Dell ML, Liow K, et al. 2001. Aggression and psychiatric comorbidity in children with hypothalamic hamartomas and their unaffected siblings. J Am Acad Child Adolesc Psychiatry, 40:696-703.

Wu J, Chang Y, Li G, et al. 2007. Electrophysiological properties and subunit composition of GABAA receptors in patients with gelastic seizures and hypothalamic hamartoma. J Neurophysiol, 98:5-15.

Wu J, Xu L, Kim DY, et al. 2005. Electrophysiological properties of human hypothalamic hamartomas. Ann Neurol, 58:371-82. 
